Pedagogía y Saberes No. 48

Universidad Pedagógica Nacional

Facultad de Educación. 2018, pp.179-181

\title{
Reseña: Formación de nación y educación
}

Reseña

Álvarez Gallego, A. (2010). Formación de nación y educación. Bogotá: Siglo del Hombre.

Ivonne Natacha Pinzón*

Para citar este artículo:

Pinzón, I. (2018). Reseña: Formación de nación y educación. Pedagogía y Saberes, 48, 179-181.

* Estudiante de la Licenciatura en Filosofía de la Universidad Pedagógica Nacional. Correo electrónico: ivonatty123@gmail.com

Código ORCID: orcid.org/0000-0002-3037-3639 
$\mathrm{L}$ os objetivos de Alejandro Álvarez Gallego (2010) en Formación de nación y educación fueron, primero, evidenciar cómo al nacionalismo le fue indispensable una estrategia educativa, y segundo, mostrar cómo la escuela se convirtió en una institución estratégica para los propósitos nacionalistas. Para el autor, el nacionalismo es "un modo de ser que ordenó el devenir político, social e intelectual en Colombia durante la primera mitad del siglo $x x^{\prime \prime}$ (p. 19). Sin embargo, para ampliar sus implicaciones, distingue, por un lado, el proyecto educativo civilizatorio caracterizado por fomentar la identidad política colectiva que se conseguiría propiciando lealtad al Estado, y por otro, el proyecto nacionalista, identificado con la construcción de una identidad política colectiva, que genera sentimientos en torno a una identidad cultural. Entonces, el propósito general de ambos proyectos era el mismo: conformar una identidad política colectiva, pero mientras que el civilizatorio empleaba como medio el cumplimiento o lealtad al Estado para reemplazar el despotismo del antiguo régimen y garantizarle al pueblo superar el oscurantismo, el nacionalista empleaba como medio la idea de una raza fuerte y un pasado común para defenderse de las amenazas económicas y culturales que representaban Estados Unidos y Europa.

Ahora bien, Álvarez plantea que, aunque para América Latina parecía haber un consenso en todos los ámbitos políticos e intelectuales, lo que distinguió el proceso nacionalista en Colombia fue que tuvo que compartir con los partidos políticos el protagonismo en la elaboración de los imaginarios de nación, de ahí que "su papel había contribuido más bien a la fractura de la nación, dado que no se le permitió representar simbólicamente la unidad pues cada gobierno utilizó el aparato del Estado para defender sus intereses partidistas" (p. 25). Esto da una pauta para comprender cómo la fractura partidista propició la violencia política y social en el país.

Posteriormente, el autor manifiesta que el nacionalismo solo era posible mediante una experiencia que movilizara emociones y actitudes, como la religión. Por lo que, según Álvarez, un valor nacional podía ser el cristianismo, en caso de que la amenaza fuera el ateísmo comunista. Así, se empezó a implementar una política educativa denominada pedagogía social, que permitiría la construcción de un proyecto político de nación. Se consideró pedagogía "porque de ella se derivaba la tesis de que los pueblos debían ser formados y conducidos hacia la realización de sus fines históricos" (p. 38), y social, dado que procedía de las ciencias sociales y estas otorgarían la clave de la identidad, pues "descubrirían los factores constitutivos de la nacionalidad que guiaba la evolución social y el momento en que se encontraba dicha trayectoria" (p. 38).

De este modo, Álvarez establece que "la educación fue la estrategia, lo social fue el objetivo, la escuela y las ciencias sociales fueron los medios y el Estado nación fue el resultado" (p. 39). En este sentido las ciencias sociales no son ajenas a la conformación del Estado-nación, pues no es gratuito que López Pumarejo mostrara la necesidad de las ciencias sociales cuando acusaba a las universidades de estar desligadas de los problemas colombianos, justamente, porque esperaba que en ellas se desarrollara, por ejemplo, la ciencia estadística, para facilitarle el trabajo al Estado y a sus dirigentes.

Más aún, la necesidad de un sentimiento nacionalista en Colombia se acrecentó cuando Estados Unidos (en plena expansión imperialista) invadió a Panamá. En ese momento empezó a convertirse -junto con su influencia: el jazz, el automóvil, la goma de mascar, entre otros elementos- en una amenaza; no solo se trataba de una invasión territorial, sino que además su influencia podría convertirse en una invasión cultural y social. En consecuencia, mediante la educación se pretendía combatir tal amenaza, a partir de

...la construcción de una cultura con fisionomía propia, donde la producción intelectual y artística afirmará la personalidad de la nación, la dotará de una espiritualidad poderosa, pues el nuevo imperialismo cultural sólo podía triunfar sobre lo que llamaron una espiritualidad anémica. (p. 71).

Así, la labor social del nacionalismo sería la de ir configurando una memoria que garantizara la sensación de que pertenecíamos a una estirpe o tradición propia.

Pero si bien es cierto que el nacionalismo (mediante la educación) posibilitaría la configuración de la memoria en los colombianos, este estaba mediado por diversos matices, que variaban según la ideología o coyuntura histórica. Verbigracia, en la tradición nacional uno de los primeros movimientos intelectuales que surgió fue el de los Modernistas, quienes a causa de su cosmopolitismo, defendían el humanismo grecolatino y comprometían sus ideas con la lucha antialcohólica y contra el trabajo infantil; su nacionalismo -aunque parezca paradójico- propendía por la inclusión del debate internacional, puesto que reivindicaban la presencia del país en la cultura occidental.

Quienes también le otorgaron otro matiz al nacionalismo fueron los Centenaristas, llamados así por haber surgido con el cambio de siglo, al 
cumplirse los cien años de la independencia. Ellos consideraban que "la modernización estaría dada por la tecnificación de la producción nacional, por la industrialización y por el urbanismo" (p. 82). Pero lo más significativo en este movimiento es que, con relación a la educación, estaban animados por la profunda convicción de que la transformación social y cultural que anhelaban necesitaba de una reforma en la escuela y en la enseñanza. Asimismo, el movimiento de los Nuevos planteó que

La larga historia de guerras civiles debía llegar a su fin y con ella la mitificación de la acción militar como parte de la misión heroica en la que los hombres se realizaban como individuos, a la vez que se justificaba la patria. Ya era tiempo, juzgaban ellos, de buscar otros referentes que le dieran sentido a la unidad nacional. [...] Habría llegado el momento de buscar otros caminos para ese proyecto de nación unitaria que se convertiría en un imperativo cultural, y sobre todo, económico. (p. 25).

Además, este movimiento se comprometió con la nacionalización del petróleo, la defensa del patrimonio nacional y hasta con algunas causas relacionadas con la reforma universitaria. Pero, pese a que los tres movimientos mencionados tenían en común el deseo de introducir reformas económicas y socioeducativas, nunca hubo acuerdo en si había que poner de relieve la tradición o la autenticidad, y finalmente, lo único que propiciaron fue confrontaciones sociales, académicas y políticas.

Llegado a este punto, el autor plantea en qué consistió, primero, el nacionalismo liberal, segundo, el nacionalismo conservador y tercero el nacionalismo católico. Este último estructuró una tesis acerca del funcionamiento de la sociedad, la cual postulaba "lo social" como aquello que no se refería a "lo político". Entonces "lo político" era un asunto del Estado y en "lo social" entraba todo lo que tuviera que ver con la condición humana, y no se limitaría a la diferencia racial o cultural. Álvarez define el nacionalismo liberal como aquel que estaba encargado de estudiar a fondo las características de la cultura popular, por lo que debió emprender una acción educativa muy amplia para, luego, propiciar una revolución que transformara las escuelas de todo el país.

El nacionalismo conservador tuvo tres elementos que lo distinguieron de los anteriores nacionalismos: en primera instancia, estaba interesado en los héroes, en especial por la figura de Simón Bolívar, dada su postura con relación a las ideas antiamericanistas; en segunda instancia, valoraban los aportes de España a la cultura y a la civilización de los países latinoamericanos, esto es, si bien creían en la identidad hispanoamericana, la consideraban posible gracias al sello de España; y en tercera instancia, asumían que la escuela debía formar un contingente que defendiera la patria de cualquier amenaza extranjera. En realidad se dedicaron a instruir militar e ideológicamente a las juventudes, proceso que estuvo absolutamente ligado al fascismo. Así que, una vez más, "en torno a esos matices se generaron las disputas por el poder más enconadas que atravesaron toda la primera mitad del siglo Xx" (p. 121).

Enseguida, Álvarez plantea que a finales de los años cincuenta algunos políticos e intelectuales empezaron a cuestionar los ideales del nacionalismo, pues les parecía que propiciaban absurdos enfrentamientos ideológicos. Simultáneamente, tales cuestionamientos causaron la institucionalización de las ciencias sociales en Colombia dado que, en su pretensión de ser modernas y científicas, estipulaban el hecho de que el nacionalismo perjudicaba la investigación histórica para juzgar los hechos.

Finalmente, el autor concluye que, por un lado, el nacionalismo fue un proyecto político-pedagógico y que en ese sentido se comprende por qué fue necesaria la nacionalización de la educación y su control por parte del Estado, lo cual desencadenó la profesionalización del maestro -donde operó un control ideológico- y la regularización de su oficio a través de un escalafón -donde operó un control administrativo-. Y, por otro, que

Una vez que el nacionalismo perdió su fuerza original, el discurso sobre el territorio volvió a cambiar. El pueblo dejó de ser la fuerza motriz de la historia y fue remplazado por los recursos naturales, estratégicos para la producción de bienes materiales, esta vez en términos de capital. La geografía pasó a ser una ciencia de los recursos, y fue el nicho de donde se desprendió más tarde la ciencia económica. (p. 151). 